\title{
Adsorptive immobilization of collagen type I on titanium oxide surfaces
}

\section{Adsorptive Immobilisierung von Kol- lagen Typ I an Titanoxidoberflächen}

Autorin: Cornelia WolfBrandstetter ${ }^{1}$

Dedicated to the $65^{\text {th }}$ birthday of Prof. Dr. Hartmut Worch

Schlagworte: Titanimplantate, Kollagen, Surface Engineering, Adsorptive Immobilisierung Keywords: titanium implants, collagen, surface engineering, adsorptive immobilization

Zitierweise dieses Beitrages: BI0materialien 2007; 8 (1) S. 32-39
Titan und dessen Legierungen werden seit langem erfolgreich als Implantatmaterial im Knochenkontakt eingesetzt. Zahlreiche Studien belegen, dass Kollagen I signifikanten Einfluss auf die Ausprägung des osteoblastären Phänotyps ausübt. Aufgrund der außerdem vorhandenen hohen strukturellen Integrität stellt eine Beschichtung mit Kollagen I eine interessante Grundmodifikation zur weiteren Verbesserung des Einheilverhaltens von Implantaten im Knochenbereich dar. Kollagen wurde in 2 Modifikationen - der monomeren Grundeinheit sowie als in vitro rekonstituiertes fibrilläres Kollagen eingesetzt.

Das Adsorptionsverhalten von Tropokollagen an Titanoberflächen zeichnet sich durch weitgehende Unabhängigkeit der adsorbierten Menge vom pH-Wert sowie von der Ionenstärke der Lösung aus. Adsorptionsdauer und Kollagenkonzentration bestimmen die Menge an adsorbiertem Kollagen.

Für die adsorptive Beschichtung von Titanoberflächen mit fibrillärem Kollagen wurden zwei Methoden vorgeschlagen. Die erste (A) beruht auf der weitestgehenden Entfernung von Tropokollagenmolekülen sowie kleinen Aggregaten, die bei einem Adsorptionsschritt mit den großen fibrillären Strukturen konkurrieren würden. Die zweite Methode (B) basiert auf der in situ Rekonstitution (B) an initial adsorbiertem Tropokollagen als Nukleationsort für weiteres fibrilläres Wachstum. Die Adsorption von fibrillärem Kollagen führte im Vergleich zur Tropokollagenadsorption zu höheren adsorbierten Mengen, einer verbesserten Stabilität bei Lagerung unter physiologischen Bedingungen sowie einem geringeren Ausma $\beta$ von Konformationsänderungen.

\section{Introduction}

One of the most common orthopedic and dental implant materials is the metal titanium and its alloys, in particular Ti6Al4V. Titanium alloys are well known for their superior mechanical properties and biocompatibility, making them desirable as surgical implant materials.

The intention of our work is generally the acceleration of implant healing after surgery with a special view towards those cases where bone healing may be impaired (i.e. systemic diseases such as diabetes or osteoporosis), improving both patient wellbeing and prolonging implant lifetime. The initial contact of implant surfaces with body fluids is an important event for adhesion of cells influencing osseointegration and long time stability as already pointed out in the first article. In this stu-

${ }^{1}$ Max-Bergmann Zentrum für Biomaterialien, TU Dresden, Institut für Werkstoffwissenschaft dy we will focus on the methodology starting with immobilisation of a highly conformational stable (structural) protein on the biomaterials surface (promotory method) as mentioned earlier. For this purpose we selected collagen I as the major protein of the extracellular matrix of bone, which not only shows excellent structural integrity but also exhibits various specific properties conductive to implant integration. Type I collagen promotes cell adhesion of osteoblasts [6], affects signal transduction by binding to the integrins $\alpha 1 \beta 1$ and $\alpha 2 \beta 1$ [22] and modulates the expression of the osteoblastic phenotype $[2,5]$. The interaction of osteoblasts with type I collagen leads to enhanced alkaline phosphatase activity [14], osteoblast-associated gene expression [5, 12, 19], and stimulation of mineralization.

The aim of the study was to investigate the adsorptive immobilization of collagen either in its monomeric form (tropocollagen) or with fibrils reconstituted in vitro. Several modified 
surfaces were characterized in matters of immobilized collagen amount, stability and conformational changes.

\section{Materials and Methods Substrates}

Discs (diameter $10 \mathrm{~mm}$, thickness $2 \mathrm{~mm}$ ) of Ti6Al4V (ASTM F 136) were mechanically polished and cleaned with $1 \%$ Triton $\mathrm{X}-100$, acetone, and 96\% ethanol, rinsed with distilled water, and air dried. Alternatively cover slips (glass, $10 \mathrm{~mm}$ diameter) were sputter-coated with titanium (99.99 \%, Goodfellow) and cleaned as above. Sputter-coated substrates were used for quantitative investigations and metal substrates were necessary for morphological investigations. Preliminary studies revealed no difference in adsorption behaviour between the two substrates. Acid-soluble calf skin collagen I (Fluka, Germany) was used for adsorption and desorption studies.

\section{Adsorption and desorption studies}

During adsorption the back side of substrates was covered with photoresist which was removed before quantification or desorption studies.

Tropocollagen: $0-1 \mathrm{mg} / \mathrm{ml}$ collagen solved in $0.01 \mathrm{M}$ acetic acid (HAc) was centrifuged at $4{ }^{\circ} \mathrm{C}$ at $30.000 \mathrm{~g}$ for $1 \mathrm{~h}$. Adsorption solutions were prepared by mixing equal volumes of cold collagen solution with cold $130 \mathrm{mM}$ phosphate buffer $\mathrm{pH}$ 2.5 - 8.0). $500 \mu \mathrm{l}$ of each adsorption solution was added to 24-well plates onto the samples lying in the wells. The adsorption was performed at $4{ }^{\circ} \mathrm{C}$. At the end of the adsorption time (15 to $1440 \mathrm{~min}$ ) the adsorption solution was removed and the samples were washed three times with water.

Fibrillar collagen: Method A (separate fibrillogenesis): In vitro reconstitution leading to collagen type I fibrils was performed by adding diluted collagen (as described above) to an equal volume of $60 \mathrm{mM}$ phosphate buffer with $0.27 \mathrm{M} \mathrm{NaCl}$ at $\mathrm{pH} 7.4$ and $4^{\circ} \mathrm{C}$. The cold solution was warmed up to $37^{\circ} \mathrm{C}$ (cold start according to Holmes et al. [9]) and kept at $37^{\circ} \mathrm{C}$ for $18 \mathrm{~h}$. The resulting gel was homogenized. Fibrils were collected by centrifugation at $5000{ }^{\mathrm{x}} \mathrm{g}$ for $15 \mathrm{~min}$, washed with water and centrifuged again. The pellet was resuspended in solution conditions with the desired collagen amount, $\mathrm{pH}$ and ionic strength. Titanium substrates were incubated in the suspension at $25^{\circ} \mathrm{C}$ for 15 min, gently shaken, washed with water, and dried.

Method B (in situ fibrillogenesis): In vitro reconstitution was performed as above with the difference that the fibillogenesis solution was kept at $4{ }^{\circ} \mathrm{C}$. A portion of this solution was added to the titanium substrates and warmed up to $37^{\circ} \mathrm{C}$ for the time of the nucleation phase (15 min) or the time of the nucleation phase and the growth phase ( $45 \mathrm{~min}$ ), respectively. After this time the solution was replaced by a new portion of fibrillogenesis solution. This cycle was repeated several times. Fibril formation was monitored turbidimetrically by measuring the absorption at $313 \mathrm{~nm}$ under chosen conditions.

Desorption studies were performed with defined coated substrates:

Tropocollagen: The adsorption solution consisted of $0.02 \mathrm{mg} / \mathrm{ml}$ or $0.2 \mathrm{mg} / \mathrm{ml}$ collagen dissolved in $10 \mathrm{mM}$ HAc mixed with equal volumes of $130 \mathrm{~m} M$ phosphate buffer ( $\mathrm{pH}$ 7.5). Adsorption was stopped after 15 or $120 \mathrm{~min}$.

Fibrillar collagen: Coating was performed with method A (separate fibrillogenesis) under conditions resulting in a homogeneous layer with intermediate collagen amounts (preparation as above, resuspension leading to $1 \mathrm{mg} / \mathrm{ml}$ collagen in $10 \mathrm{mM}$ phosphate buffered saline (PBS).

Desorption was carried out by incubating the coated samples differing times with $500 \mu \mathrm{l}$ of desorption solution: either PBS or cell culture medium - Dulbecco's Minimal Essential Medium (DMEM) with $10 \%$ fetal calf serum (FCS) at $37^{\circ} \mathrm{C}$ or $4{ }^{\circ} \mathrm{C}$, respectively. Because of the short halftime of the ${ }^{131} \mathrm{I}$, desorption studies with tropocollagen were conducted only up to $48 \mathrm{~h}$.

\section{Labeling of tropocollagen with $\mathrm{Na}^{131} \mathrm{I}$ and quantification of adsorbed tropocollagen}

$200 \mu \mathrm{l}$ of cold collagen solution $(2 \mathrm{mg} / \mathrm{ml}$ in $0.01 \mathrm{M}$ Acetic acid, $4{ }^{\circ} \mathrm{C}$ ) were mixed with $150 \mu \mathrm{l}$ of $130 \mathrm{mM}$ cold phosphate buffer $\left(\mathrm{KH}_{2} \mathrm{PO}_{4} / \mathrm{NaHPO}_{4}, \mathrm{pH} 7.0,4{ }^{\circ} \mathrm{C}\right)$ immediately before iodination. $20 \mu \mathrm{l} \mathrm{Na}{ }^{131} \mathrm{I}$ (Amersham) and one iodobead (Pierce), prerinsed in the same buffer, were added. After $15 \mathrm{~min}$ with gentle shaking at room temperature the reaction solution was separated from the beads with a syringe. The bead was rinsed with $50 \mu \mathrm{l}$ of the phosphate buffer and this solution was added to the iodinated collagen solution. The radiolabeled collagen was purified by dialysis against PBS for $20 \mathrm{~min}$ at $4{ }^{\circ} \mathrm{C}$ followed by $20 \mathrm{~h}$ against $0.01 \mathrm{M}$ Acetic acid $\left(4{ }^{\circ} \mathrm{C}, 3\right.$ changes of solution), performed in dialysis cups (Slide-A-Lyzer, MWCO 10.000, Pierce). The purity was verified by thin layer chromatography. The resulting protein concentration was estimated by the LOWRY method [26]. To ascertain that ${ }^{131} \mathrm{I}$-labeling had no effect on the adsorption properties, different ratios of labeled to unlabeled collagen were investigated and the amount of adsorbed collagen measured under identical adsorption conditions. No significant preferential adsorption of labeled or unlabeled collagen could be detected. The radioactivity of bound collagen was measured directly on the surface with a $\gamma$-Counter. The collagen amount was calculated using a standard curve obtained by dried quantities of adsorption solution on identical substrates. Due to the short halftime of ${ }^{131} \mathrm{I}$ the standards were measured immediately prior to the samples.

\section{Quantification of adsorbed fibrillar collagen}

Protein concentration adsorbed to titanium was quantified using the Sirius Red method [24]. Briefly, samples were incubated in a saturated solution of picrinic acid with $0.1 \%$ of Sirius Red (Promochem) for $1 \mathrm{~h}$ at room temperature. After washing extensively with $0.01 \mathrm{M} \mathrm{HCl}$, the stain was dissolved in a defined volume of $0.1 \mathrm{M} \mathrm{NaOH}$ and measured at $540 \mathrm{~nm}$ (Spectrafluor Plus, Tecan, Switzerland).

\section{Fourier transformed infrared spectroscopy}

FTIR spectra were recorded with an FTS 2000 (Perkin Elmer, Wellesley MA, USA). Adsorbed collagen was investigated in reflection mode as well as with attenuated total reflection spectroscopy (ATR). ATR crystals were sputter-coated with titanium (99.99\%) and adsorption was performed on top of this surface. Adsorption solutions of i) $0.5 \mathrm{mg} / \mathrm{ml}$ tropocollagen in $65 \mathrm{mM}$ phosphate buffer $\mathrm{pH} 7.4$ or ii) a fibrillar suspension of approx. $0.5 \mathrm{mg} / \mathrm{ml}$ in $65 \mathrm{mM}$ phosphate buffer $\mathrm{pH} 7.4$ (method A) were dropped in the reservoir on top of the crystal. After 15 minutes the surfaces were rinsed with water and dried. Reference spectra were collected from transmission studies of tropocollagen and fibrillar collagen solutions in $\mathrm{D}_{2} \mathrm{O}$ as well as dried fibrillar collagen.

Morphological investigations were carried out with a digital scanning electron microscope (SEM) DSM 925 Gemini (Zeiss, Germany). All chemicals were of analytical grade and purchased from Sigma-Aldrich Chemie GmbH, (Germany) if not stated otherwise. The water was obtained from a Purelab device (U.S.Filter, Massachusetts, USA). 


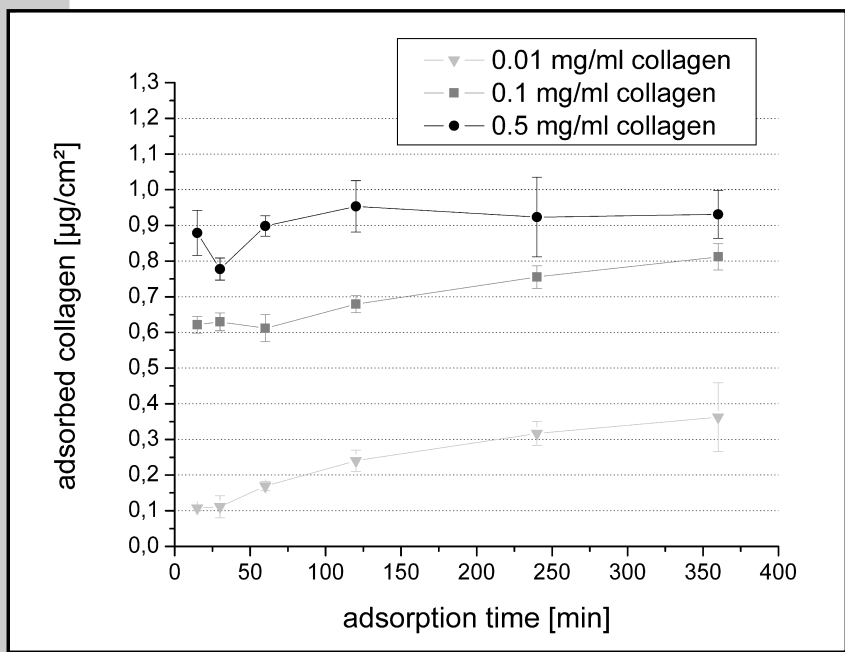

Fig. I.: Adsorbed tropocollagen amount for various collagen concentrations depending on adsorption time. Adsorption in $65 \mathrm{mM}$ phosphate buffer (pH $\left.7.4,4^{\circ} \mathrm{C}\right)$

\section{Results}

\section{Adsorption and desorption behaviour of tropocollagen}

Because of the higher mobility and fewer steric restrictions of the monomeric form, the adsorption and desorption studies were performed first with tropocollagen. The preparation of single molecules was evaluated with AFM as shown before [26]. In order to avoid aggregation during investigations, the experiments were carried out at $4{ }^{\circ} \mathrm{C}$. Regarding the rate of collagen adsorption, a major uptake of the total absorbed amount was observed after 15 minutes of adsorption (Fig. 1). Remaining up to 30 minutes at a pseudo-equilibrium stage, a slower uptake followed which was not yet completed after six hours in the case of low collagen concentration $(0.01 \mathrm{mg} / \mathrm{ml})$. In case of the highest concentration $(0.5 \mathrm{mg} / \mathrm{ml})$ a subsequent decrease at 30 minutes instead of the plateau phase followed by a slow uptake stage was realized. Under these conditions a maximum adsorbed amount of $0.9 \pm 0.08 \mu \mathrm{g} / \mathrm{cm}^{2}$ was determined. The influence of $\mathrm{pH}$ on adsorption was studied for two collagen concentrations ( 0.01 and $0.1 \mathrm{mg} / \mathrm{ml})$ resulting in an intermediate adsorbed amount of $0.2 \mu \mathrm{g} / \mathrm{cm}^{2}$ and accordingly

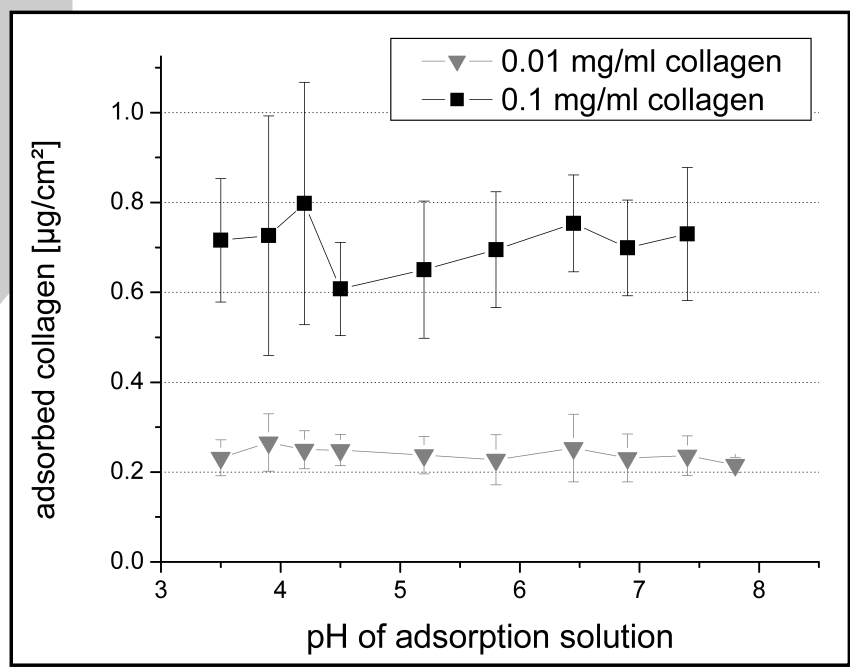

Fig 2:: Adsorbed collagen amount depending on $\mathrm{pH}$ of adsorption solution. Adsorption in $65 \mathrm{mM}$ phosphate buffer of varying $\mathrm{pH}\left(4^{\circ} \mathrm{C}\right)$ with two different collagen concentrations.

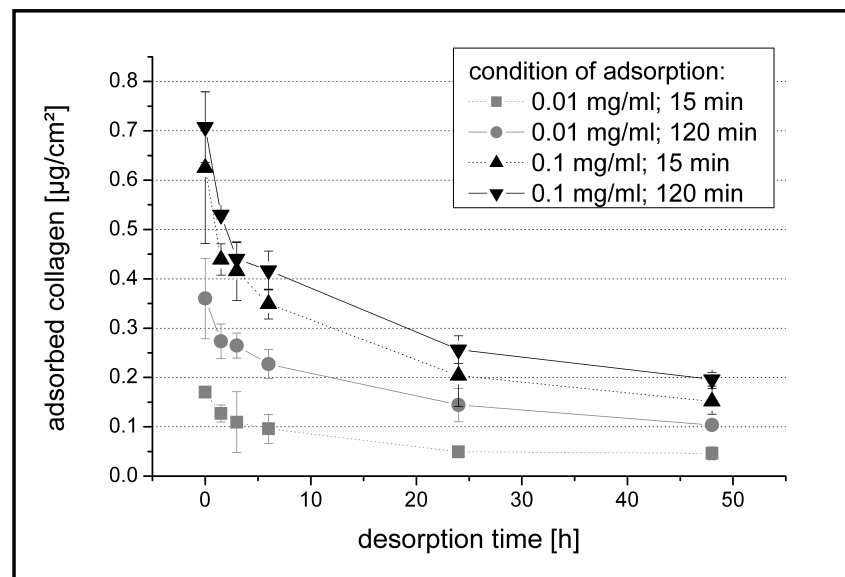

Fig 3.: Remaining amount of adsorbed collagen after incubation with PBS (above) or cell culture medium containing $10 \%$ fetal calf serum (below) using collagen coated substrates differing in applied concentration and adsorption time. Adsorption in $65 \mathrm{mM}$ phosphate buffer $\left(\mathrm{pH} 7.4,4^{\circ} \mathrm{C}\right)$. Desorption at $37^{\circ} \mathrm{C}$.

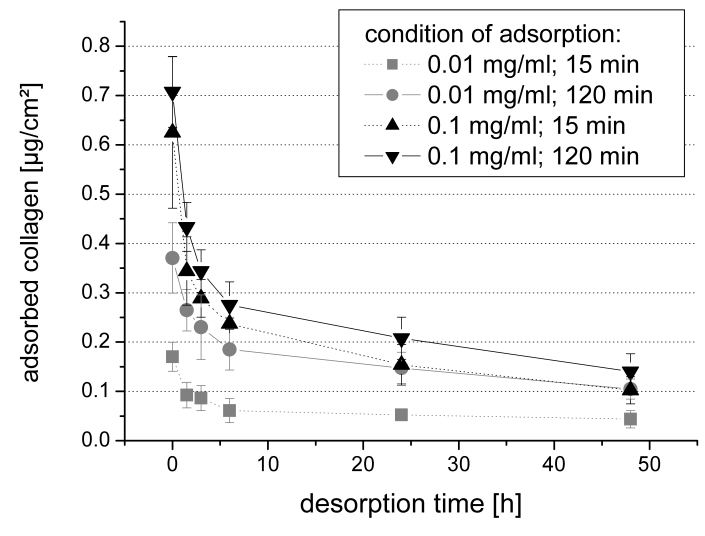

a quite high adsorbed amount of $0.8 \mu \mathrm{g} / \mathrm{cm}^{2}$ near maximal adsorption. In both cases no great impact of $\mathrm{pH}$ could be observed (Fig. 2). The slight maximum at neutral pH values ( $\mathrm{pH}$ $6.5-7.5$ ) could be verified by a separate experiment measured with ELISA [26].

Desorption studies were performed with defined coated substrates either in protein free PBS or in cell culture medium (DMEM) containing serum proteins. For tropocollagen four coating conditions were selected, which differed in concentration of adsorption solution $(0.01 \mathrm{mg} / \mathrm{ml}$ and $0.1 \mathrm{mg} / \mathrm{ml})$ and adsorption time (15 min and $120 \mathrm{~min}$ ). These parameters had been found to make the greatest impact on amount adsorbed. Large portions of previously adsorbed collagen were released from all coated surfaces independently of adsorbed amount as demonstrated in Fig. 3 a and b. Adsorption states with longer adsorption times (120 min) resulted in a slightly decreased percentage of desorbed collagen. The presence of proteins from serum-containing medium decreased the amounts of collagen remaining compared to incubation with PBS.

\section{Adsorption and desorption behaviour of fibrillar collagen}

Adsorption experiments with fibrillar collagen revealed a competitive adsorption with a relatively mobile fraction of numerous molecular/oligomer collagen species and the high molecular fibrils. (Molecular/oligomeric species were regulary found 


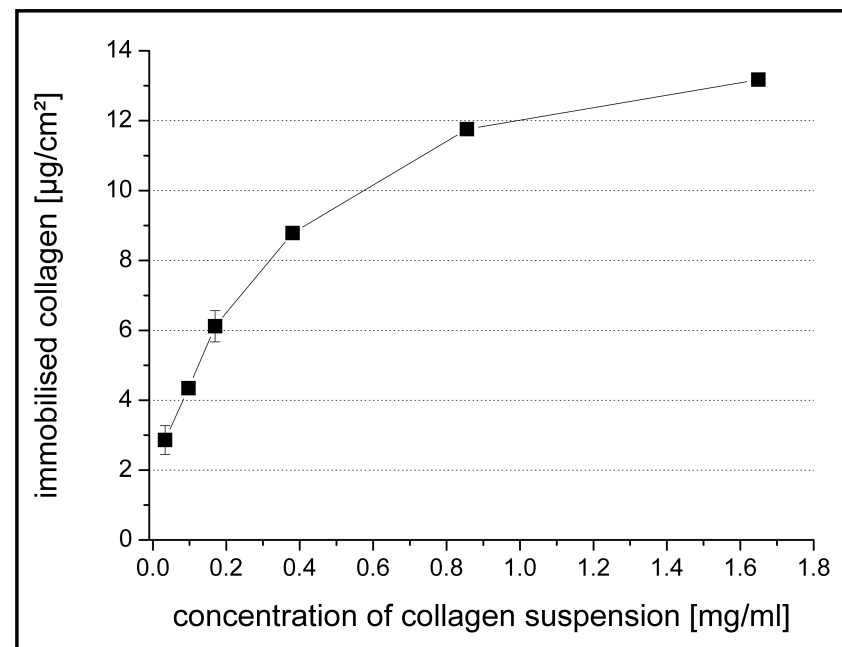

Fig. 4.: Adsorbed amount of fibrillar collagen depending on concentration of collagen suspension (resuspendend in PBS, adsorption at $22^{\circ} \mathrm{C}$ for 15 min under gentle shaking).

in in vitro reconstitution solutions.) As shown from SEM studies, fibrils are not capable of binding at sites which are already covered by smaller collagen I units. Based on the findings of tropocollagen adsorption, two methods are derived for improved immobilization of fibrillar collagen: A) adsorption from fibrillar solutions that are vastly free from tropocollagen and oligomeric species B) the utilization of previously adsorbed tropocollagen as nucleation sites for further fibrillar growth. For the first method (A), the fibrillar network obtained was homogenized and fibrils were collected after centrifugation as described above. The pellet of fibrillar collagen was resuspended to form suspension of the desired composition. First the influence of concentration was investigated. Similarly to the adsorption behaviour of tropocollagen, the concentration of fibrils has a great impact on amount adsorbed. Increasing the concentration up to $1 \mathrm{mg} / \mathrm{ml}$ resulted in a pronounced increase of collagen adsorbed (Fig. 4). At concentrations higher than $1 \mathrm{mg} / \mathrm{ml}$ only a small further increase was observed. The adsorption equilibrium was reached very quickly. After a few seconds the surface was covered with fibrillar aggregates. Gentle shaking aided the homogeneous distribution of the fibrillar

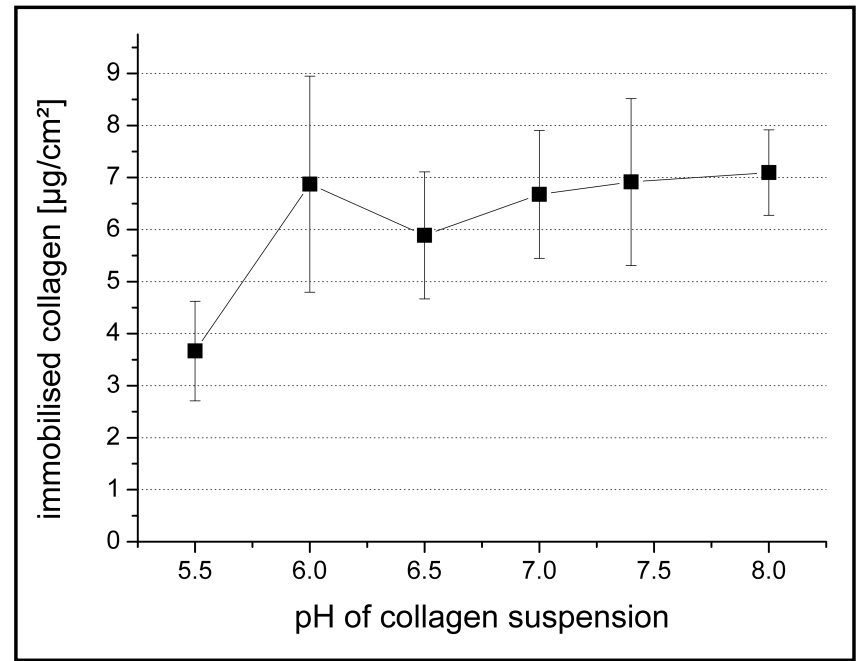

Fig. 5.: Adsorbed amount of fibrillar collagen depending on $\mathrm{pH}$ (resuspendend in phosphate buffer of varying $\mathrm{pH}$, adsorption at $22^{\circ} \mathrm{C}$ for 15 min under gentle agitation).

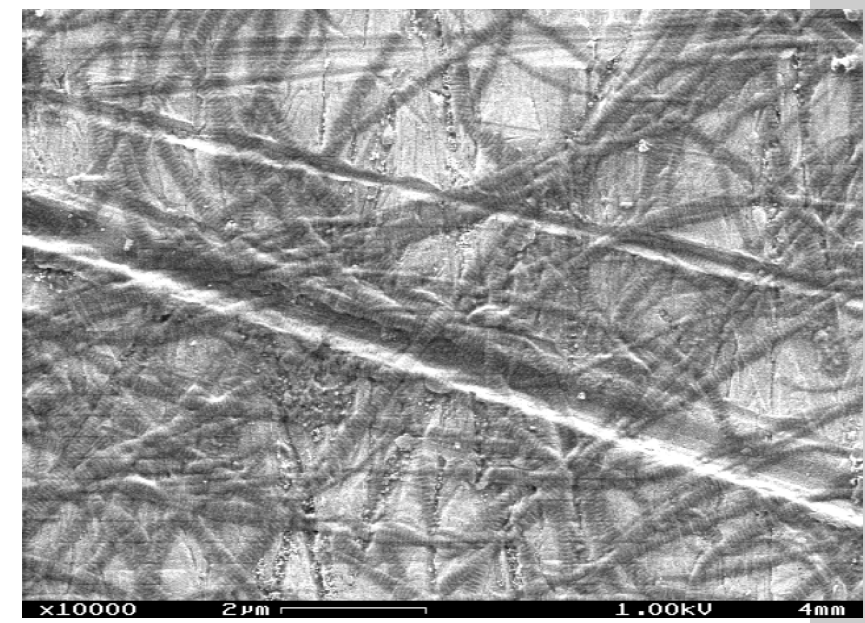

Fig. 6.: Collagen fibrils adsorbed to Ti6Al4V discs. Fibrils generated with 500 $\mu \mathrm{g} / \mathrm{ml}$ collagen at $37^{\circ} \mathrm{C}$ and immobilized using method $\mathrm{A}$.

network. Incubations longer than 15 min did not raise the adsorbed amounts (data not shown). Comparing the adsorbed amounts of tropocollagen and fibrillar collagen with the same applied collagen concentrations, the use of fibrillar collagen resulted in a nearly 10 fold increase in collagen immobilized. Investigations on the impact of $\mathrm{pH}$ were restricted by the disassembly of reconstituted fibrils at $\mathrm{pH}$ values lower than 5 . Between pH 6.0 and 8.0 no differences in amount adsorbed were found (Fig. 5). Likewise the ionic strength did not influence the adsorbed amount of collagen [26] (data not shown). Morphological studies with SEM revealed a homogenous distribution of fibrillar aggregates (Fig. 6). Adsorbed fibrils retained their typical banding. Apparently uncovered sites have been shown to be coated with smaller aggregates which could not be completely removed by centrifugation steps.

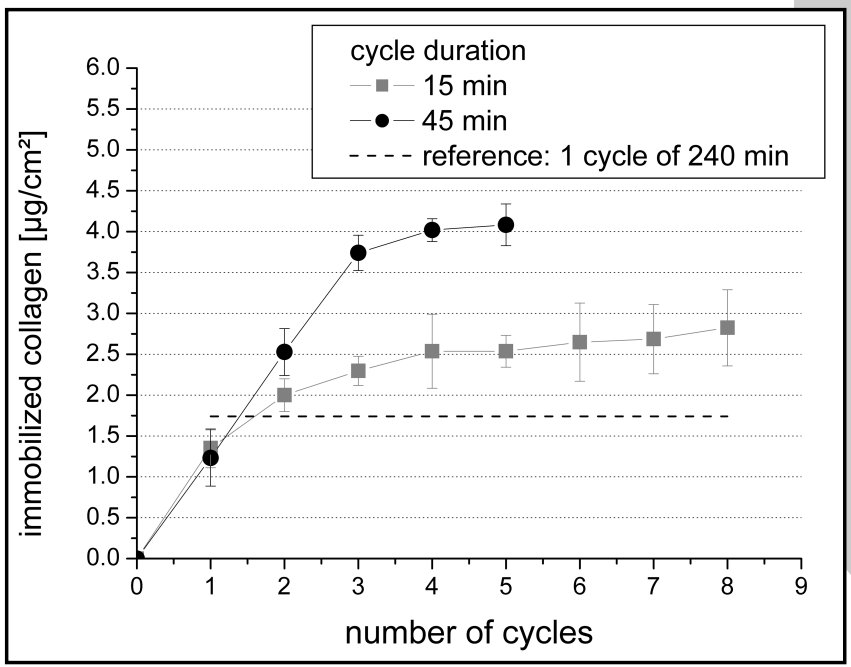

Fig. 7.: Immobilized collagen amount after repeated addition of fresh reconstitution solution. Fibrillogenesis in situ $(0.5 \mathrm{mg} / \mathrm{ml}$ collagen in $65 \mathrm{mM}$ phosphate buffer $\mathrm{pH} 7.4$ at $37^{\circ} \mathrm{C}$ ).

The proposed method (B) is based on the finding that tropocollagen adsorbs at high concentrations in a tightly packed arrangement where single molecules are fixed at the surface only with parts of the whole molecule (see discussion). The "free" ends of the molecules should be available as nucleation sites for further fibrillar growth. The titanium surfaces were 


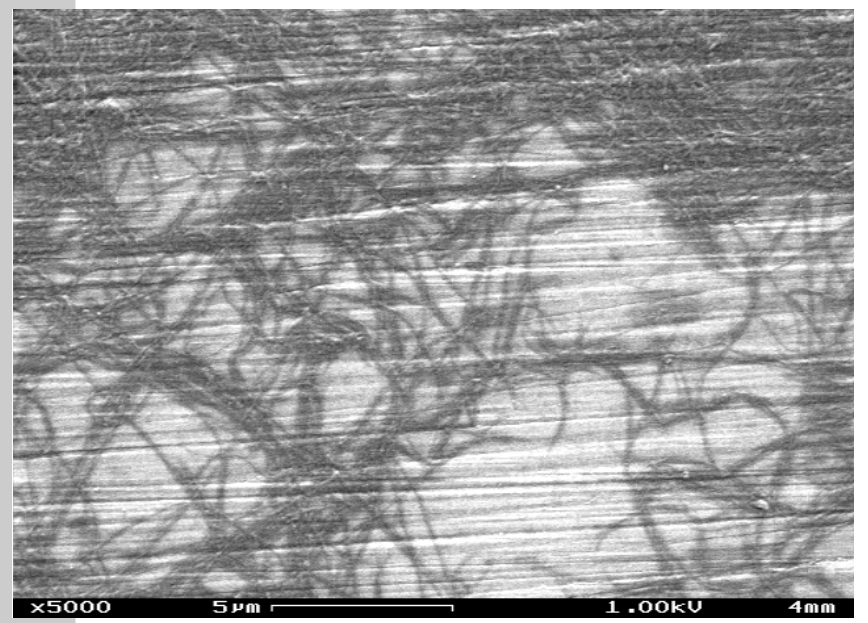

Fig. 8.: Immobilized collagen amount after repeated addition of fresh reconstitution solution. Fibrillogenesis in situ $(0.5 \mathrm{mg} / \mathrm{ml}$ collagen in $65 \mathrm{mM}$ phosphate buffer $\mathrm{pH} 7.4$ at $37^{\circ} \mathrm{C}$ ) for above) 8 cycles of nucleation phase or below) 5 cycles of nucleation and growth phase.

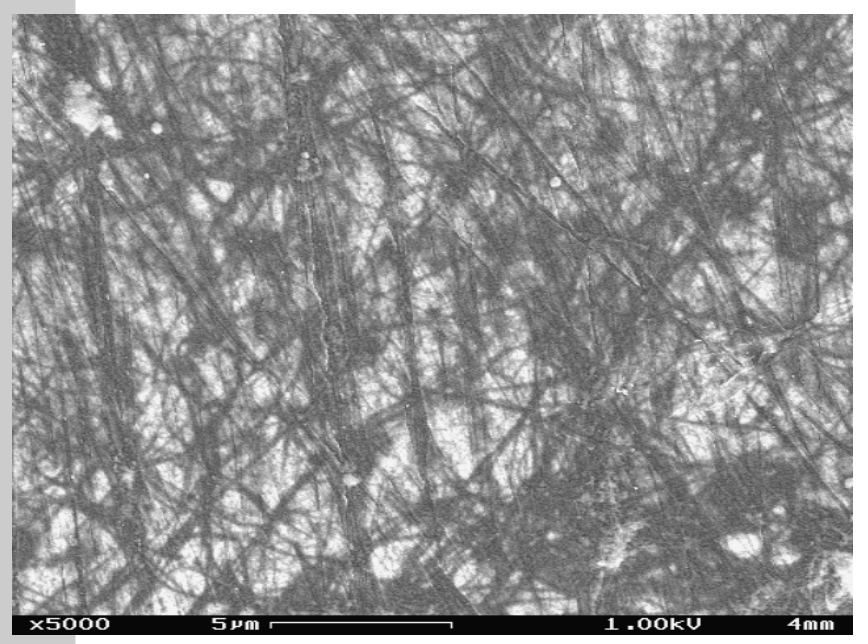

brought in contact with fibrillogenesis solutions of defined composition (collagen concentration, $\mathrm{pH}$, ionic strength) consisting initially of tropocollagen molecules. Warming up the samples together with the fibrillogenesis solution allowed fibrillogenesis in situ to begin. Amounts of immobilized collagen determined after one cycle for the time of nucleation (15 min) or the time of nucleation and additional growth phase (45 min) were only marginally higher than the value after adsorption from comparable tropocollagen solutions (Fig. 7 versus Fig. 1). Repeated cycles of warming up with fresh fibrillogenesis solutions increased the immobilized collagen amounts, whereby after 4 cycles a plateau was reached. Once the plateau phase had been reached, fibrillar structures with typical banding pattern could be observed for both applied cycle types (Fig. 8 a and b). In case of combined nucleation and growth phase the uptake per cycle and the resulting plateau value of immobilized collagen were significantly higher in contrast to the merely repeated nucleation phase. Comparable amounts of immobilized collagen could not be achieved by simple fibrillogenesis in situ. Administering the fibrillogenesis solution for a complete fibril formation cycle of $240 \mathrm{~min}$ at the titanium surface resulted in an immobilized collagen amount not much higher than that of the corresponding first cycle. Besides, only few fibrils were attached to the surface.

Desorption studies were undertaken with samples prepared

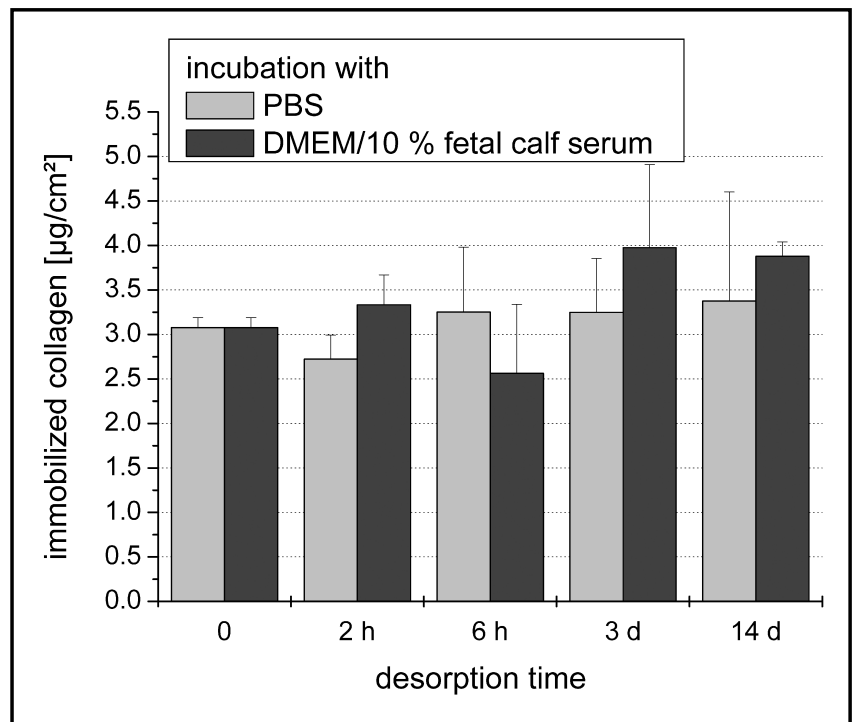

Fig. 9. Remaining amount of immobilized fibrillar collagen after incubation in PBS or cell culture medium at $37^{\circ} \mathrm{C}$. Fibrils were generated with $0,5 \mathrm{mg} / \mathrm{ml}$ collagen at $37^{\circ} \mathrm{C}$ and immobilized with method $\mathrm{A}$.

with method (A) only. For these coatings an excellent stability could be observed. Neither incubation of samples with PBS nor with serum-containing cell culture medium resulted in changes of adsorbed collagen amounts within the investigated time interval of 2 weeks (Fig. 9).

\section{Conformational studies}

Spectra of adsorbed tropocollagen and adsorbed fibrillar collagen were compared to unbound fibrillar collagen (Fig. 10). For both adsorbed collagen preparations distinct changes in the amide I region were realized. The relative intensity of the shoulder at $1630 \mathrm{~cm}^{-1}$ to the peak at $1658 \mathrm{~cm}^{-1}$ was increased. The maximum of the amide II band shifted from 1558 to 1546 $\mathrm{cm}^{-1}$. In general, the intensity of the amide I region was diminished in proportion to the amide II and amide III region. This effect was especially pronounced for tropocollagen. From comparison of tropocollagen with fibrillar collagen in solution as well as dried fibrils with humid fibrils, it can concluded that these changes occur as a result of the adsorption process [26].

\section{Discussion}

To understand the adsorption phenomena, it is helpful to imagine the geometrical situation at the surface. Based on the dimensions of the tropocollagen molecule $(300 \mathrm{~nm}$ in length with a thickness of $1.5 \mathrm{~nm}$ ) the collagen mass which would correspond to a monolayer assuming a flat tightly packed arrangement would be $0.1 \mu \mathrm{g} / \mathrm{cm}^{2}$. The maximal adsorbed amount obtained was determined to be $0.9 \mu \mathrm{g} / \mathrm{cm}^{2}$. This means that at a high concentration of collagen in the adsorption solution the molecules are only able to adsorb with a part/some parts of its entire length on the substrate surface. Exclusive immobilization of collagen molecules via protein-protein interactions is unlikely because under the selected conditions, no aggregation of collagen molecules could be observed for the corresponding time intervals [26]. The contact area of a single molecule which interacts with $1 / 10$ of its length amounts to about $45 \mathrm{~nm}^{2}$. In contrast, the minimum areas of interface $(\Delta \mathrm{A})$ which are required to stabilize adsorbing molecules against desorption range between 1 to $2 \mathrm{~nm}^{2}$ for various proteins and are nearly independent of the size or molecular weight of the proteins [13]. Once "connected" with the surfaces the molecu- 


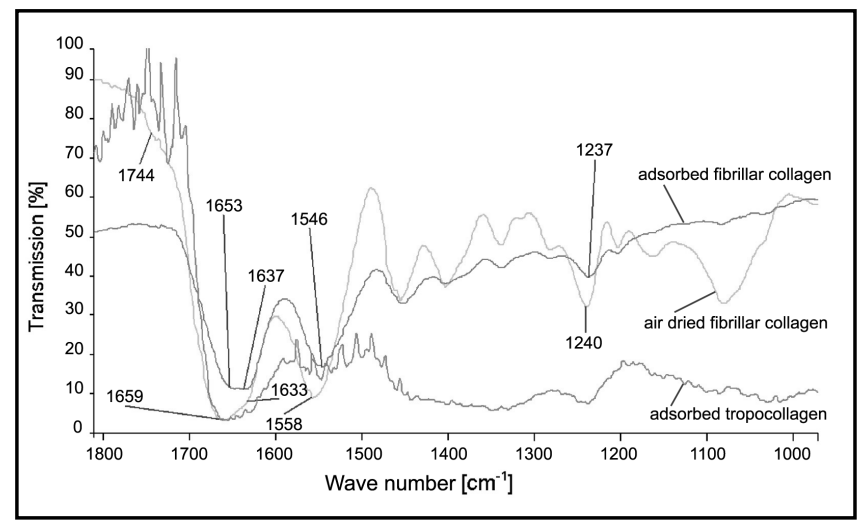

Fig. I0.: IR spectra (obtained by attenuated total reflection) of adsorbed tropocollagen and fibrillar collagen in contrast to unbound air dried fibrillar collagen.

les can optimize their interfacial interactions by time-dependent orientation and potential conformational changes. Hence the collagen possesses outstanding potential for a sufficient contact area due to its high surface area to volume ratio. Furthermore, large parts of the molecules are free and should be available for interactions with solution components. Applying low collagen concentrations, the molecules have the opportunity to form a lot of interactions with the surface which should result in an increased contact area and a diminished length of accessible parts of collagen molecules (see Fig. 11). Indeed, preliminary investigations with quartz microbalance revealed different thicknesses of the resulting collagen/waterfilm depending on the adsorbed amount of collagen. For the maximum amount of collagen adsorbed, namely $0.94 \mu \mathrm{g} / \mathrm{cm}^{2}$, a thickness of approximately $135 \mathrm{~nm}$ was estimated, which corresponds to nearly $1 / 2$ of the molecule length. Applying lower collagen concentrations $(0.01 \mathrm{mg} / \mathrm{ml})$ resulted in a steady increase of the protein layer during adsorption up to $75 \mathrm{~nm}$ after 1000 minutes.

The observed overshoot for adsorption from high collagen concentrations is in accordance with other investigations of protein adsorption $[20,23]$ and may be explained by time-dependent surface-induced transitions. Molecules with optimized protein-substrate-interactions consume surface areas of their neighbours, which are less tightly adhered to the surface. On the basis of the assumptions discussed above, desorption phenomena can be explained. Protein adsorption has been shown to be irreversible in a number of investigations [1, 3, 23] by simple incubation in water or buffer solutions. Adsorbed proteins exhibit a great number of interaction sites. All interaction sites have to be lifted off in order for the protein to desorb. This is statistically improbable. Exchange is a different matter. Therefore collagen desorption during incubation in PBS has to be regarded as exchange of loosely bound collagen by adjacent molecules. Remaining molecules gain more interaction sites by displacing other molecules. Starting from high initial adsorbed amounts, the remaining collagen amount tended towards the theoretical amount of the monolayer which could be verified by ELISA measurement over a desorption period of up to seven days [26]. For low collagen amounts obtained with low concentration and short adsorption time, rearrangements resulted in values beneath the monolayer, presumably due to irregular distribution of the molecules which arrived first, which prevents the high order packing assumed for monolayer calculations.

Based on the assumptions concerning tropocollagen adsorption described above, two methods for immobilization of fibrillar collagen were proposed and successfully realized. Separating fibrils reassembled in vitro from remaining monomeric/oligomeric species (method A) has proved to be a simple method to increase the adsorbed amount and to improve the distribution of fibrils at the surface. Immobilization with method (B) clearly demonstrated that an adsorbed layer of tropcollagen can be utilized for further fibrillar growth at the free ends of the molecules. Simple exposure of surfaces to fibrils self-reconstituting in situ gave rise to fibrillar growth adjacent to the surface leading to poor fibril attachment to the surface as well as large areas covered with small aggregates. Only through the repeated exchange of reconstitution solutions could assembly of fibrils proceed at the surface. Due to the simpler procedure and higher amounts of accessible collagen, method (A) was used for adsorption and desorption studies and furthermore for subsequent cell experiments [8].

In contrast to adsorbed tropocollagen, immobilized fibrillar collagen possesses a much higher number of interaction sites. Neither with PBS nor with serum-containing medium desorption of collagen was observed within the time interval investigated.

The overall adsorption process for both tropcollagen and fi-

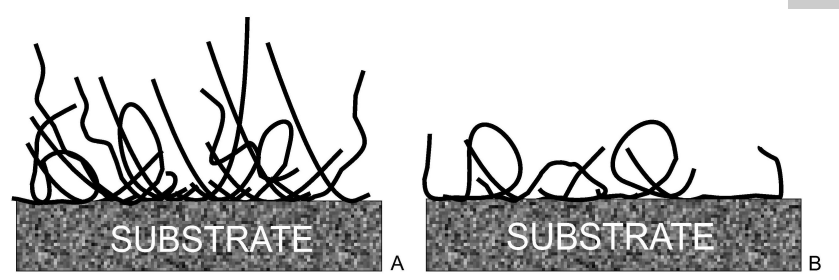

Fig. II. Proposed model for adsorbed tropocollagen molecules after adsorption from a) concentrated or b) diluted collagen solutions

brillar collagen has been shown to be nearly independent of $\mathrm{pH}$ and ionic strength. As known from surface investigations, the titanium and Ti6Al4V surfaces utilized exhibit hydrophobic properties with contact angles of $82^{\circ}$ and $76^{\circ}$ respectively [18, 26]. Photoelectron spectroscopy revealed a thin organic layer [26] consisting mainly of carbohydrates which is in agreement with other investigations on titanium oxide surfaces [10, 11]. Repulsive electrostatic forces at $\mathrm{pH}$ values beneath 4.5 (isoelectric point of oxide layers on the titanium substrates used [26]) or above 6.0 (isoelectric point of collagen [26]) did not affect the adsorption process. These findings are consistent with other studies which demonstrated that electrostatic interactions are relevant solely in the case of hydrophilic surfaces and rigid proteins $[15,16]$.

Adsorption of proteins onto solid surfaces is often accomplished by structural changes of adsorbed molecules $[1,3,15]$. Infrared spectroscopy serves as a quite useful method to evaluate structural changes in the secondary structure of proteins. Several studies point out that different proportions of $\alpha$-helix and $\beta$-sheet result in distinct positions and relative intensities of amid I, II and III bands [21,25]. Because of its unique threedimensional structure the triple-helical collagen does not fit to the models of globular proteins. Payne and Veis [17] established a special model for collagen and compared native collagen with heat denatured collagen. Changes in the substructure of amide I, especially the decrease of the band at 1660 $\mathrm{cm}^{-1}$ and the related increase at $1643 \mathrm{~cm}^{-1}$, were found to occur as a result of denaturation. Such changes in the substructure of the amide I region have been found for both collagen coatings. Additional shifts in the amide II region and a general decrease of the intensity of the amide I region clearly in- 
dicated conformational changes in adsorbed collagen. The extent of relative intensity changes was more pronounced for tropocollagen. This may be explained by a greater number of molecules/parts of molecules which are not in direct contact in the case of adsorbed fibrillar collagen.

\section{Conclusion}

It has been shown that tropocollagen as well as fibrillar collagen can be utilized to coat implant surfaces made of titanium or titanium alloys quite homogeneously. Immobilization of fibrillar collagen is recommended due to the higher amounts of adsorbed collagen which can be achieved, the improved stability under physiological conditions and the minor extent of conformational changes. It should be emphasized that no covalent coupling is necessary for stable immobilization of fibrillar collagen. Using the described collagen modification as basis, a more sophisticated approach consists of integrating non-collageneous components such as glycosaminoglycans $[4,7,27]$ into the fibrils, creating an artificial matrix that not only resembles the naturally occuring one more closely, but the effects of which on adherent cells surpasses that of unmodified collagen [4]. Furthermore growth factor binding and release can be influenced by altering matrix composition, administering external growth factors [27] or by capturing secreted molecules at the implantation site.

\section{Acknowledgement}

Financial support by the Deutsche Forschungsgemeinschaft (WO 494/5-1) is gratefully acknowledged.

\section{Abstract}

Titanium and its alloys are favoured as implant materials for bone contact. Collagen type I as the main organic component of bone has been shown to be important in the regulation of the osteoblast phenotype and is therefore an interesting substance for the surface modification of titanium implants. Starting from this point, the aim of the study was to investigate the adsorptive immobilisation of collagen type I on titanium and Ti6Al4V surfaces depending on different adsorption parameters. Collagen was used in two forms: the monomeric unit (tropocollagen) and in vitro reconstituted fibrils. Coated substrates were comparatively characterized with respect to amount of collagen immobilized, stability and changes in conformation. It has been shown that tropocollagen as well as fibrillar collagen can be utilized to coat implant surfaces quite homogeneously. Previously adsorbed tropocollagen could successfully used as nucleation sites for further fibrillar growth. The adsorption of fibrillar collagen compared to tropocollagen resulted in higher amounts of bound collagen, excellent stability in desorption studies and better resistance against conformational changes as evaluated by IR-investigations.
\end{abstract}

\section{References}

[1] Andrade JD, V. Hlady. Protein adsorption and materials biocompatibility: A tutorial review and suggested hypotheses. In: Autorenkollektiv, ed. Biopolymers/ Non-Exclusion HPLC. Berlin: Akademie Verlag, pp. 1-64, 1987.

[2] Andrianarivo AG, Robinson JA, Mann KG, Tracy RP. Growth on type I collagen promotes expression of the osteoblastic phenotype in human osteosarcoma MG-63 cells. J Cell Physiol 153 (2): 256-65, 1992.

[3] Bentaleb A, Haikel Y, Voegel JC, Schaaf P. Kinetics of

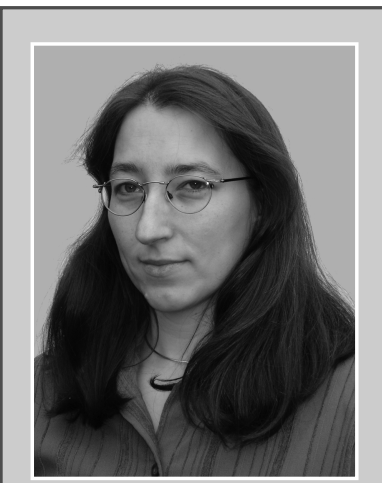

\section{Dr. Cornelia Wolf-Brandstetter}

Korrespondenzadresse:

Max-Bergmann Zentrum für Biomaterialien TU Dresden Budapester Str. 27 01069 Dresden E-Mail: Cornelia.Wolf-Brandstetter@tu-dresden.de

\section{Akademischer Lebenslauf}

$1988-1994$

Studium der Lebensmittelchemie an der Technischen Universität Dresden (Diplom und 1. Staatsexamen)

1994 -1995 2. Staatsexamens an der Landesuntersuchungsanstalt für das Gesundheits- und Veterinärwesen in Sachsen (Standort Dresden)

Seit 1996 Wissenschaftliche Mitarbeiterin an der TU Dresden, Institut für Werkstoffwissenschaft (Max-Bergmann-Zentrum für Biomaterialien)

2004 Promotion zum Dr. rer. nat. („Adsorptive Immobilisierung von Kollagen Typ I an Titanoxidoberflächen“)

the homogeneous exchange of alpha-lactalbumin adsorbed on titanium oxide surface. J Biomed Mater Res 40 (3): 449-57, 1998.

[4] Bierbaum S, Douglas T, Hanke T, Scharnweber D, Tippelt S, Monsees TK, Funk RH, Worch H. Collageneous matrix coatings on titanium implants modified with decorin and chondroitin sulfate: characterization and influence on osteoblastic cells. J Biomed Mater Res A 77 (3): 551-62, 2006.

[5] Celic S, Katayama Y, Chilco PJ, Martin TJ, Findlay DM. Type I collagen influence on gene expression in UMR106-06 osteoblast-like cells is inhibited by genistein. J Endocrinol 158 (3): 377-88, 1998.

[6] Cooper LF, Handelman B, McCormack SM, Guckes AD. Binding of murine osteoblastic cells to titanium disks and collagen I gels: implications for alternative interpretations of osseointegration. Int J Oral Maxillofac Implants 8 (3): 264-72, 1993.

[7] Douglas T, Heinemann S, Bierbaum S, Scharnweber D, Worch H. Fibrillogenesis of collagen types I, II, and III with small leucine-rich proteoglycans decorin and biglycan. Biomacromolecules 7 (8): 2388-93, 2006.

[8] Geissler U, Hempel U, Wolf C, Scharnweber D, Worch H, Wenzel K. Collagen type I-coating of Ti6Al4V promotes adhesion of osteoblasts. J Biomed Mater Res 51 (4): 752-60, 2000. [9] Holmes DF, Capaldi MJ, Chapman JA. Reconstitution of collagen fibrils in vitro; the assembly process depends on the initiating procedure. 8 (3): 161, 1986.

[10] Keller JC, Stanford CM, Wightman JP, Draughn RA, Zaharias R. Characterizations of titanium implant surfaces. III. J Biomed Mater Res 28 (8): 939-46, 1994.

[11] Lausmaa JBK, H. Mattsson, H. Odelius. Multi-Technique Surface Characterization of Oxide Films on Electropolished and Anodically Oxidized Titanium. Applied Surface Science 45 (3): 189-200, 1990.

[12] Lynch MP, Stein JL, Stein GS, Lian JB. The influence of 
type I collagen on the development and maintenance of the osteoblast phenotype in primary and passaged rat calvarial osteoblasts: modification of expression of genes supporting cell growth, adhesion, and extracellular matrix mineralization. Exp Cell Res 216 (1): 35-45, 1995.

[13] Macritchie F. Proteins at interfaces. Adv Protein Chem 32: 283-326, 1978.

[14] Masi L, Franchi A, Santucci M, Danielli D, Arganini L, Giannone V, Formigli L, Benvenuti S, Tanini A, Beghe F, et al. Adhesion, growth, and matrix production by osteoblasts on collagen substrata. Calcif Tissue Int 51 (3): 202-12, 1992.

[15] Norde W, J.P. Favier. Structure of adsorbed and desorbed proteins. Colloids and Surfaces 64: 87-93, 1992.

[16] Norde W, Lyklema J. Why proteins prefer interfaces. J Biomater Sci Polym Ed 2 (3): 183-202, 1991.

[17] Payne KJ, Veis A. Fourier transform IR spectroscopy of collagen and gelatin solutions: deconvolution of the amide I band for conformational studies. Biopolymers 27 (11): 174960, 1988.

[18] Roessler S, D. Scharnweber, C. Wolf, H. Worch. Investigation of the adsorption of tropocollagen type I on titanium and Ti6Al4V. Journal of Adhesion Science and Technology 14 (3): 453, 2000.

[19] Shi S, Kirk M, Kahn AJ. The role of type I collagen in the regulation of the osteoblast phenotype. J Bone Miner Res 11 (8): 1139-45, 1996.

[20] Soderquist ME, Walton AG. Structural changes in proteins adsorbed on polymer surfaces. 75 (2): 386, 1980.

[21] Susi H, Ard JS, Carroll RJ. The infrared spectrum and water binding of collagen as a function of relative humidity. Biopolymers 10 (9): 1597-604, 1971.

[22] Takeuchi Y, Nakayama K, Matsumoto T. Differentiation and cell surface expression of transforming growth factor-beta receptors are regulated by interaction with matrix collagen in murine osteoblastic cells. J Biol Chem 271 (7): 3938-44, 1996.

[23] van Dulm P, W. Norde. The adsorption of human plasma albumin on solid surfaces, with special attention to the kinetic aspects. J Colloid Interface Sci 91: 248-255, 1983.

[24] Walsh BJ, Thornton SC, Penny R, Breit SN. Microplate reader-based quantitation of collagens. Anal Biochem 203 (2): 187-90, 1992.

[25] Walton AG, Deveney MJ, Koenig JL. Raman spectroscopy of calcified tissue. Calcif Tissue Res 6 (2): 162-7, 1970.

[26] Wolf-Brandstetter C. Adsorptive Immobilisierung von Kollagen Typ I an Titanoxidoberflächen. PhD thesis, Technical University, 2004.

[27] Wolf-Brandstetter C, Lode A, Hanke T, Scharnweber D, Worch H. Influence of modified extracellular matrices on TI6AL4V implants on binding and release of VEGF. J Biomed Mater Res A 79 (4): 882-94, 2006. 